\title{
A mulher no telejornalismo esportivo: ponderações sobre o programa Globo Esporte São Paulo
}

\section{The woman in sports telejournalism: weights on the Globo Sport São Paulo Program}

\author{
Jéssica Beatriz Backer Gebhardt ${ }^{1}$, Michele Negrini ${ }^{2}$, Christian Dias Nunes ${ }^{3}$
}

\section{Resumo}

O artigo tem como objetivo pesquisar a participação da mulher no telejornalismo esportivo, com foco no programa Globo Esporte São Paulo. Vamos analisar a relevância das matérias realizadas por jornalistas mulheres e verificar os valores notícia e critérios de noticiabilidade presentes em cada reportagem, fazendo um parâmetro comparativo com o que é apresentado por jornalistas homens, tendo como método a Análise de Conteúdo. Pretendemos retomar a história da mulher no telejornalismo e fazer uma análise histórica da mulher na sociedade. A questão de gênero também será abordada, assim como um breve histórico telejornalístico.

Palavras-Chave: Telejornalismo. Esporte. Mulher.

\begin{abstract}
The article aims to research the participation of women in sports news, with focus on the GloboEsporte São Paulo program. We will analyze the relevance of the material produced by women journalists and verify the news values and news reporting criteria in each report, making a parameter with what is presented by male journalists. We intend to revisit the history of women in television journalism and make a historical analysis of women in society. The issue of gender will also be addressed, as well as a brief history of television journalism.
\end{abstract}

Keywords: Television journalism. Sport. Woman.

Jornalista pela Universidade Federal de Pelotas. Email: jessicabackesgeb@gmail.com

2 Doutora em Comunicação pela PUCRS. Pós-doutorado pela UFBA, no programa de Pós-Graduação em Comunicação e Cultura Contemporâneas. Professora da Universidade Federal de Pelotas. Email: mmnegrini@yahoo.com.br

3 Colaborador do trabalho. Acadêmico de Jornalismo da Universidade Federal de Pelotas. Email: christiandiasnunes@gmail.com 


\section{Introdução}

Durante muito tempo, no âmbito da vida social, as mulheres na maioria das vezes foram meras coadjuvantes, voltadas a atividades domésticas, como cuidar do lar e dos filhos. Homens e mulheres desempenhavam papéis muito distintos na sociedade. Ao longo dos anos, através de diversas lutas sociais, como reivindicação por melhores condições de trabalho, salários iguais para homens e mulheres e exigência de direito ao voto, as mulheres foram conquistando a sua autonomia e, hoje, exercem funções que antes eram restritas aos homens. No entanto, essa luta pela igualdade é contínua, pois ainda há muito a ser conquistado. No que se refere a alguns assuntos ou lugares, ainda é evidente a distinção dos gêneros. No futebol, assunto dominado pela maioria dos homens, a mulher ainda busca mais credibilidade, seja no esporte em si ou na prática jornalística. É evidente o grande número de homens em redações e coberturas jornalísticas esportivas, porém as mulheres estão conquistando cada vez mais esse espaço e a participação delas em telejornais esportivos está em constante crescimento.

Diversos programas televisivos esportivos têm dado espaço para as mulheres nesse meio. $\mathrm{O}$ Globo Esporte (GE) é um deles. O programa é exibido pela Rede Globo desde agosto de 1978, de segunda a sábado, às $12 \mathrm{~h} 50 \mathrm{~min}$. Atualmente, o GE tem 15 edições próprias: uma edição de rede que é gravada e gerada pela TV Globo Rio de Janeiro para todo o Brasil - com exceção aos estados do Amazonas, Bahia, Ceará, Distrito Federal, Goiás, Mato Grosso, Mato Grosso do Sul, Minas Gerais, Paraná, Pernambuco, Rio de Janeiro, Rio Grande do Sul, São Paulo e Santa Catarina, que possuem edições regionais.

O programa Globo Esporte foi escolhido para este estudo tendo em conta a constante (e crescente) presença de mulheres, não só na ancoragem, mas também na produção de reportagens. A partir disso, o presente artigo tem como objetivo refletir e problematizar a presença da mulher no jornalismo esportivo, analisando o programa Globo Esporte São Paulo, delimitando e propondo a verificação da relevância das notícias apresentadas pelas mulheres no programa, através da observação dos principais critérios de noticiabilidade das notícias esportivas apresentadas por elas em relação às notícias apresentadas por jornalistas homens.

\section{A Mulher na Sociedade}

O modelo e a ideia de uma sociedade baseada no patriarcado colocaram a mulher em uma situação submissa, de ter que cumprir suas obrigações de acordo com as regras impostas a elas. Desde que nascemos, somos ensinadas sobre o que fazer e sobre o que não fazer, de acordo com o nosso gênero. Meninas devem usar rosa e meninos devem usar azul. O doutrinamento de gênero impregnado na sociedade nos faz pensar que "ser menino" ou "ser menina" fazem parte de uma hierarquização, onde aprendemos que meninos podem fazer mais coisas e que as meninas devem ser submissas e mais cuidadosas. E assim acontece em diversas esferas da nossa sociedade. Seja no mercado de trabalho, em casa e até mesmo nas escolas.

Segundo Oliveira (2007), a luta para que as mulheres obtenham legitimidade na sociedade vem, efetivamente, desde o século XIX, com a revolução industrial, onde elas reivindicavam por melhores condições de trabalho e pelos seus direitos como cidadãs, pois embora pudessem trabalhar fora de casa, ainda recebiam salário inferior ao dos homens. No início do século XX, no Brasil, as mulheres obtiveram o direito de trabalhar e também conquistaram o direito ao voto. Atualmente, a desigualdade entre gêneros na sociedade diminuiu no decorrer dos anos, graças à luta daquelas que não se calaram perante o preconceito.

Em meados dos anos 1950 e 1960, as mulheres viviam na esfera do lar, enquanto os homens trabalhavam. De acordo com Carvalho (2011), elas eram vistas, no âmbito da construção social da 
época, como inferiores aos homens. Historicamente, o poder sempre foi praticado e exercido pelos homens, pois as mulheres eram consideradas subalternas, devendo obediência e respeito às pessoas do sexo masculino (CARVALHO, 2011, p. 145). Era como se elas, biologicamente, fossem destinadas a cuidar do lar e dos filhos. O movimento feminista, instaurado no início dos anos 1960, permitiu à mulher reverter a situação, conquistando seu espaço, seus direitos e se inserindo em diversos circuitos culturais - incluindo universidades.

Por volta dos anos 1960 e 1970, com o instauro da ditadura militar, a figura do homem era atribuída ao poder, principalmente institucional. A censura imposta pela ditadura não permitia a abordagem de assuntos como aborto, orgasmo, anticoncepcionais, divórcio e até mesmo câncer de mama.

De acordo com Woitowics e Pedro (2009), o período da ditadura no Brasil contribuiu para o fortalecimento de inúmeros movimentos sociais que lutavam contra a repressão da época. $\mathrm{O}$ feminismo se fortaleceu nesse período mais radical da ditadura, contando com o apoio de mulheres que já haviam sido exiladas. A imprensa alternativa ${ }^{4}$ foi grande aliada na mobilização das mulheres na defesa de seus direitos e foi um meio importante para que as mulheres se manifestassem e criassem um discurso próprio, capaz de fazer questionamentos e promover mudanças (WOITOWICS; PEDRO, 2009, p. 45). A autonomia do movimento feminista durante a ditadura fez com que a sociedade repensasse o papel da mulher, a partir de discussões significativas que fomentavam a importância da democracia e dos direitos das mulheres enquanto cidadãs. Embora a ditadura tenha se findado, as marcas no autoritarismo da época ainda permanecem, juntamente com o conservadorismo da sociedade.
Segundo pesquisa de dados do Instituto Brasileiro de Geografia e Estatística (IBGE) de 2009, mesmo com o grande avanço das mulheres em adentrar o mercado de trabalho, ainda existem dificuldades a serem superadas. A participação delas ainda é maior nos grupamentos que incluem a administração pública e serviços domésticos - neste último elas eram quase maioria absoluta.

Retomando a questão esportiva, as mulheres já conquistaram o direito de participar de competições de esporte e também podem trabalhar na cobertura esportiva jornalística, algo que não era comum, salvo exceções, até a década de 1970. Ainda há muito que evoluir, mas muitos passos já foram dados em busca da igualdade entre homens e mulheres.

Elas trabalham fora e têm direito de tomar suas decisões na sociedade. A participação ativa da mulher ainda é escassa em alguns setores da sociedade, porém muito já foi conquistado. Atualmente, as mulheres ocupam cargos que antes eram exclusivos ao homem. As mulheres se organizaram para que sua voz fosse ouvida, lutando contra as diferenças de gênero, para melhorar sua qualidade de vida e obter melhores condições de trabalho, para se firmarem na sociedade civil como pessoas de direito e públicas (CARVALHO, 2011, p. 152).

\section{Os Critérios de Seleção de Notícia no Telejornal}

Segundo Traquina (2005), os jornalistas fazem uso dos valores-notícia para selecionar os acontecimentos do mundo real. Na comunidade jornalística são os critérios de noticiabilidade que norteiam o processo de seleção de notícias e definem o que é importante e o que não é. Levando em

\footnotetext{
${ }^{4}$ A imprensa alternativa foi um espaço importante de crítica ao regime militar, de divulgação de denúncias, e de debate das organizações de esquerda. Por meio do humor, da análise política ou da informação, esses jornais e revistas alternativos cumpriram um papel fundamental de oposição e resistência à ditadura no Brasil. Jornais como "Brasil Mulher" (1975 - 1979), "Nós Mulheres" (1976 - 1978) e "Mulherio" (1981 - 1987) são exemplos de imprensa alternativa na época. Eram usados como meio de publicação do movimento feminista para levantar as principais bandeiras das mulheres (WOITOWICS, 2006).
} 
consideração essa afirmação, os jornalistas devem determinar o que vai, ou não, ser noticiado.

Traquina (2005, p. 63) define os critérios de noticiabilidade como "conjunto de valores-notícia que determinam se um acontecimento, ou assunto, é susceptível de se tornar notícia”. Para Motta (2002), os valores-notícia operacionalizam a prática jornalística nas redações, sugerindo o que deve ser selecionado para ser noticiado e o que deve ser omitido. São esses fatores que determinam a seleção das notícias. Portanto, pretende-se, através desse conceito, realizar um estudo comparativo sobre os critérios de noticiabilidade das matérias realizadas por mulheres e por homens no Globo Esportes, com o objetivo de verificar se há igualdades entre os gêneros na profissão.

Este tópico pretende discorrer sobre os critérios de noticiabilidade para dar bases à comparação do estudo entre as mulheres e homens, pois a presente pesquisa procura responder às seguintes questões: quais notícias são produzidas pela mulher no programa Globo Esporte São Paulo? Elas são pautas relevantes? Como essas notícias são selecionadas e classificadas como mais importantes?

Ainda, segundo Traquina (2005, p. 63), os critérios de noticiablidade são os conjuntos de critérios e operações que fazem com aquela notícia tenha valor jornalístico.

“[...] Assim, os critérios de noticiabilidade são o conjunto de valores-notícia que determinam se um acontecimento, ou assunto, é suscetível de se tornar notícia, isto é, de ser julgado como merecedor de ser transformado em matéria noticiável e, por isso, possuindo "valor notícia"".

De acordo com Wolf (1995), valores-notícia (newsvalue) são componentes dessa noticiabilidade. Ou seja, os valores-notícia definem o que será noticiado pelo veículo. Assim, é possível perceber que algumas notícias possuem mais valores do que outras, pois os valores-notícia definem a hierarquia dos fatos noticiados.
Os valores-notícia possuem algumas características de definição do que será notícia. Segundo Traquina, a morte é um dos principais fatores para que um fato seja noticiado. O autor ainda cita como valor-notícia de seleção - critérios substantivos - a notoriedade do ator principal do fato; "O nome e a posição da pessoa são importantes como fator de noticiabilidade" (TRAQUINA, 2005, p. 80); a proximidade com o acontecimento; a relevância do conteúdo divulgado e o impacto que isso terá na vida das pessoas; a novidade que um fato irá apresentar; o tempo, em relação à atualidade "[...] há vinte anos isto aconteceu e publica-se hoje uma notícia sobre esse acontecimento porque aconteceu neste mesmo dia há x anos" (TRAQUINA, 2005, p. 81); a notabilidade de um assunto, "[...] isto é, a qualidade de ser visível, de ser tangível" (TRAQUINA, 2005, p. 82); o inesperado também é outro valor-notícia importante no meio jornalístico, é o que surpreende; o conflito ou a controvérsia, "[...] isto é, a violência simbólica, como uma disputa verbal entre líderes políticos" (TRAQUINA, 2005, p. 84); a infração é outro valor-notícia, o qual está ligado à violência. Segundo Traquina, a infração refere-se à violação, a transgressão de regras. O autor ainda discorre sobre a simplificação de notícias e a visibilidade das informações para que determinado fato seja ou não noticiado.

Todos esses critérios de noticiabilidade listados por Traquina podem ser aplicados no jornalismo em geral. No entanto, se pensarmos as características específicas de cada veículo de comunicação, podemos observar que os critérios podem variar de acordo com o formato e características de cada veículo. No telejornalismo, por exemplo, segundo Negrini e Brandalise (2015), a presença de imagens é primordial assim como:

“[...] a possibilidade de uma narrativa televisual de forma espetacular e humanizada; a disponibilidade de fontes especializadas no assunto enfocado e sua disposição para falar na $\mathrm{TV}$; o destaque do fato ocorrido no contexto de abrangência do telejornal 
e o potencial caráter melodramático relacionado ao fato". (NEGRINI; BRANDALISE, 2015, p. 9).

Entende-se, então, que o uso de imagens interfere na seleção das notícias, isso porque a televisão é um meio visual, seu telespectador espera receber imagens do fato noticiado, o oposto do rádio, por exemplo.

Assim como qualquer produto jornalístico, o telejornalismo esportivo também é norteado pelo critério de noticiabilidade, valores-notícia. O que pode ser notícia no noticiário esportivo? De acordo com Sousa (2002), tudo o que é factual, que desperta o interesse do público, aquilo que atinge o maior número de pessoas, "quanto maior for o número de pessoas atingidas por um acontecimento, maior sua possibilidade de tornar-se notícia" (SOUSA, 2002, p. 5);o inusitado ou curioso, "por convenção, aquilo que foge da rotina do dia a dia é notícia" (SOUSA, 2002, p. 10); a novidade e a presença de bons personagens, "o noticiário esportivo em televisão se pauta cada vez mais pelos personagens que protagonizam as histórias noticiáveis, sejam eles celebridades ou não" (SOUSA, 2002, p. 8).

Além disso, a presença de imagens é imprescindível, “com o esporte, apelo das imagens tem uma importância redimensionada no noticiário e elas são a notícia em si: o registro do gol, da falta, da bela jogada" (SOUSA, 2002, p. 4); assim como apresentar uma boa narrativa, "causar impacto emocional e apresentar um potencial espetacular para fazer frente aos demais produtos televisivos" (SOUSA, 2002, p. 2). Rivalidade, provocação e conflito são elencados pela autora, a qual ressalta que "a noticiabilidade também se pauta pelo conflito que se instala nas situações noticiáveis" (SOUSA, 2002, p. 11); e a notícia em função do resultado inesperado também é elencado na relação, afinal "o resultado ainda é apontado como o grande critério de seleção, especialmente quando é inesperado ou improvável" (SOUSA, 2002, p. 11).

Por fim, o humor, o espetáculo e entretenimento são considerados fatores que podem fazer com que um fato vire notícia. "De alguma forma, o telejornal esportivo se constitui como um momento de diversão em meio à informação, justamente por causa das características da notícia com que trabalha" (SOUSA, 2002, p. 11).

\section{A Mulher no Telejornalismo Brasileiro}

No passado, as redações dos telejornais eram dominadas por homens. Segundo Liidtke (2012), "por séculos e séculos, a imprensa teve bigodes, chapéu, cheiro de cigarro e sapatos pretos. Onde estaria o outro modelo da espécie humana?". Somente na década de 1950, as mulheres passaram a ocupar espaços dominados por homens, entre eles as redações jornalísticas.

A figura feminina foi surgindo na televisão de forma gradual. Segundo Scott (2013), as mulheres eram as garotas-propagandas, locutoras e videomoças das emissoras de televisão. No entanto, com o "desaparecimento dos patrocinadores exclusivos, a evolução técnica, o videotape, a sofisticação dos comerciais filmados e dinamização da linguagem publicitária” (RIXA, 2000, p. 60), essas funções foram extintas.

Scott (2013) resgata que a TV Tupi, ainda nos anos 1950, apresentava programas destinados ao universo feminino. Os programas "Revista Feminina" e "No mundo feminino" eram apresentados por Lolita Rios e Maria de Lourdes Lebert, respectivamente (RIXA, 2000). O “TV Mulher”, exibido durante seis anos na TV Globo-SP, foi um marco nos anos 80. Segundo Vera Paternostro (2006), foi um momento histórico para o feminismo no Brasil porque o programa abordava pautas que até o momento não eram exibidas na televisão, com comportamento sexual, direitos e saúde da mulher.

Segundo Scott (2013), apesar de inicialmente estarem em minoria nas redações, as mulheres fizeram parte da história da televisão desde o início. Maria Edith Mendes foi a primeira mulher a sair às ruas como repórter. A atriz e redatora Vera Rossi 
foi a primeira mulher a apresentar um telejornal. Ela fazia parte do Informativo Panair, na TV Rio. O telejornal Ultra Notícias, da TV Globo, era apresentado por Natália Timberg ao lado de Hilton Gomes, em 1966 (LORÊDO, 2000).

Na década de 1960, o Jornal de Vanguarda, que contou com a participação da jornalista Gilda Müller, ficou conhecido por transmitir um conteúdo "criativo, irreverente e informativo". Na Espanha, ganhou o Prêmio Ondas como o melhor telejornal do mundo" (LORÊDO, 2000, p. 66-67). No âmbito esportivo, segundo Scott (2013), Íris Lettieri foi a primeira mulher a ler notícias sobre futebol. A iniciativa ocorreu no telejornal Perspectiva, da TV Tupi, em 1969. Em 1997, uma mulher narrou uma partida de futebol pela primeira vez: Luciana Mariano. A partir daí muitas jornalistas começaram a aparecer em programas esportivos de forma mais natural e exercendo funções antes chamadas de "masculinas".

O Jornal Nacional, da Rede Globo, em mais de quarenta anos de história (foi exibido pela primeira vez em 01 de setembro de 1969), teve quatro apresentadoras titulares de sua bancada: Lilian WiteFibe, Fátima Bernardes, Patrícia Poeta e Renata Vasconcelos (NEGRINI; BRANDALISE, 2015, p. 1). Sônia Maria foi pioneira na bancada do Jornal Nacional, em novembro de 1971 (RIXA, 2000). Além das apresentadoras de bancada, uma das figuras femininas mais importantes do telejornal é a "mulher do tempo", Sandra Annemberg teve destaque nesta função na década de 1990. Hoje, esse papel é desempenhado pela jornalista Maju Coutinho. Glória Maria também se destacou na Rede Globo, assim como Ana Paula Padrão e Fátima Bernardes, uma das mais conhecidas apresentadoras de telejornal brasileira.

Todas as jornalistas citadas - e muitas outras que não foram mencionadas, que lutaram atrás das câmeras - fizeram parte da construção do telejornalismo brasileiro. Elas participaram direta ou indiretamente de todo o processo, enfrentando preconceitos, mas, sobretudo, vencendo os obstáculos, com profissionalismo e responsabilidade.

\section{A Mulher no Telejornalismo Esportivo}

A ascensão dos meios de comunicação facilitou as transmissões de diversas partidas esportivas, possibilitando o público a assistir ou a ouvir coberturas em tempo real. Segundo Coelho (2003), trabalhar com jornalismo esportivo não é tão simples quanto parece. Um jornalista esportivo é, antes de tudo, um jornalista. Ainda segundo Coelho (2003), é uma editoria que ainda sofre muito preconceito dentro do jornalismo por ser considerada "uma editoria menos importante".

O fato é que, mesmo com todas as evoluções ocorridas na sociedade até agora, as mulheres, muitas vezes, ainda encontram dificuldades em trabalhar na editoria.

"As mulheres tiveram (e ainda têm) que lutar bastante para receber o mesmo reconhecimento que seus colegas de trabalho recebem, sem distinção, sem que seu trabalho seja qualificado como bom ou ruim apenas pelo fator biológico; mas sim, pelo conteúdo apresentado" (AGUIAR, 2012, p. 35)

Culturalmente, as mulheres muitas vezes são vistas como frágeis perante a imagem do homem. No futebol, esporte priorizado nas coberturas esportivas, elas só adentraram em 1894, quando foi criado o time "Senhoras Britânicas", em Londres (AGUIAR, 2012). Segundo Aguiar (2012, p.26), "acreditava-se que o esforço físico poderia fazer mal às mulheres, que eram tratadas como seres frágeis a ser mantidos em segurança para gerarem filhos fortes e saudáveis". No Brasil, a participação das mulheres no futebol aconteceu somente em 1979, quando elas ganharam o direito de praticar o esporte, em uma briga judicial com o Conselho Nacional de Desportos.

As mulheres conquistaram muitos direitos ao longo dos anos, como o direito ao voto, por exemplo. 
Paralelo às conquistas dos direitos, as mulheres também conquistaram diversas áreas no mercado de trabalho, muitas dominadas por homens. De acordo com Baggio (2012, p. 29), "hoje, o número de jornalistas credenciadas, em comparação ao ano de 1980, é 12 vezes maior, aumentando de oito para 90 mulheres jornalistas que trabalham com futebol". Apesar disso, a equidade entre os gêneros ainda está longe de ser atingida.

Durante a década de 1970, poucas mulheres ocupavam cargos em redações jornalísticas. Ao longo dos anos, esse cenário foi se modificando, principalmente pelo fato de que as mulheres começaram a possuir um grau de escolaridade maior: mais mulheres tinham acesso à educação. No entanto, as editorias preenchidas pelas mulheres eram as editorias consideradas "não sérias". Era inimaginável uma mulher falar sobre política, por exemplo.

Mesmo assim, com esses obstáculos, algumas mulheres destacaram-se profissionalmente dentro das redações da época. Albeniza Garcia fez reportagens policiais para o jornal "O Globo" e Adalgisa Nery trabalhou na editoria de política do jornal "Última Hora" (ROCHA; ABREU, 2006).

$\mathrm{Na}$ editoria de esportes, de acordo com Coelho (2003), as mulheres eram designadas somente às pautas de esporte amador. Uma escolha tendo em vista que as mulheres não teriam capacidade de cobrir o esporte profissional.

Maria H. Rangel trabalhou no jornal "Gazeta Esportiva" em 1947 e foi a primeira mulher a enfrentar os obstáculos impostos na época, e "nenhum dos jornalistas que ali estavam poderia imaginar que a moça, chamada Maria Helena Nogueira Rangel, era a mais nova contratada do veículo, a primeira mulher a cobrir a área de esportes no Brasil [...]" (PRIZIBISCZKI, 2007).

As mulheres adentraram no mundo do jornalismo esportivo somente na década de 1970. De acordo com Ribeiro (2007), até então, as mulheres não conseguiam adentrar o universo das transmissões esportivas. Porém, no radiojornalismo, vale ressaltar, uma grande novidade que pretendia derrubar os preconceitos existentes na época. Roberto Montoro, dono da Rádio Mulher, decidiu criar um programa esportivo com uma equipe forma exclusivamente por mulheres (RIBEIRO, 2007).

Segundo Ribeiro (2007), o programa esportivo se manteve por cinco anos, apesar do grande preconceito vindo de jogadores ou jornalistas na época - dentro e fora dos gramados. Desmotivadas, nenhuma delas seguiu na carreira esportiva e, muito tempo depois, uma mulher integrou uma equipe do rádio esportivo novamente: Regiani Ritter. Em 1983, a jornalista passou a cobrir as folgas dos repórteres que faziam a cobertura dos clubes paulistanos, na Rádio Gazeta (REZENDE, 2014). Regiani era repórter e comentarista e chegou a conquistar o prêmio de melhor jornalista esportiva do estado de São Paulo, em 1991 (RIBEIRO, 2007, p. 221).

$\mathrm{Na} \mathrm{TV}$, a pioneira foi a jornalista Isabela Scalabrini (MEMÓRIA GLOBO, 2013). Ela foi a primeira repórter a trabalhar na Rede Globo nesta editoria, na década de 1980, no Globo Esporte, no Rio de Janeiro. Scalabrini cobria diversas modalidades esportivas, exceto o futebol - considerado uma área de atuação masculina. Em 1986, Regiani Ritter foi a primeira mulher repórter a atuar em um campo de futebol. A jornalista foi uma das primeiras, depois de muito tempo, a adentrar o território dominado pela figura do homem, além de comentar o esporte no programa Mesa Redonda, da TV Gazeta.

Atualmente, é notável o aumento das mulheres no telejornalismo esportivo. Até mesmo no esporte houve um crescimento considerável de mulheres participando de diversas competições que antes eram restritas a elas. Porém, os preconceitos e as dificuldades estão sempre presentes, de alguma forma ou outra.

"Percebe-se que o público começa a não considerar tão estranho uma mulher em um programa 
sobre futebol. Contudo, mesmo as mulheres tendo mais espaço nessa editoria, ainda se fala muito pouco ou quase nada do futebol feminino, ou seja, os preconceitos e as dificuldades não desapareceram por completo" (AGUIAR, 2012, p. 37).

O cenário do jornalismo esportivo em relação à figura feminina se modificou muito ao longo dos anos, porém ainda existe uma diferença gritante em relação aos homens. De acordo com Coelho (2003), $10 \%$ de mulheres trabalham nos editoriais de esporte pelo país. Se formos comparar com o início do jornalismo, perceberemos que a participação feminina era quase nula e que esse é um bom resultado para as mulheres que como os homens são amantes do esporte (BRAVO, 2009).

\section{Perspectivas Metodológicas}

A metodologia utilizada para o desenvolvimento desta pesquisa é embasada no método de Análise de Conteúdo, de Laurence Bardin. Os dados serão obtidos através da análise de quatro edições do Globo Esporte São Paulo. Na análise será observado o tempo destinado para reportagens feitas por homens e mulheres, além dos critérios de noticiabilidade que cada reportagem possui.

Julgou-se pertinente fazer uma aferição qualitativa e, ao mesmo tempo, quantitativa para tentar identificar os critérios de noticiabilidade presentas nas seguintes edições do Telejornal Esportivo Globo Esporte São Paulo: - Edição do dia 13 de outubro de 2015, apresentada pelo jornalista Ivan Moré; - Edição do dia 22 de outubro de 2015, apresentada pelo jornalista Ivan Moré.

\section{Análise de Conteúdo}

A análise de conteúdo surgiu nos Estados Unidos no início do século XX com o objetivo de ser usada como instrumento de interpretação de textos e "seus primeiros experimentos estavam voltados para a comunicação de massas" (GOMES, 2003, p. 74 apud AGUIAR, 2012, p. 39). De acordo com Laurence Bardin (2009), a Análise de Conteúdo é:

\begin{abstract}
Um conjunto de técnicas de análise das comunicações visando obter, por procedimentos, sistemáticos e objetivos de descrição do conteúdo das mensagens, indicadores (quantitativos ou não) que permitam a inferência de conhecimentos relativos às condições de produção/recepção (variáveis inferidas) destas mensagens.[...] A intenção da análise de conteúdo é a inferência de conhecimentos relativos às condições de produção (ou, eventualmente, de recepção), inferência esta que recorre a indicadores (quantitativos ou não) (BARDIN, 2009, p. 38).
\end{abstract}

Segundo Bardin (2009), a Análise de Conteúdo é composta por três etapas de análise. A primeira fase é a "pré-análise". Nela é feito um levantamento dos dados para organização da análise, elaboração de hipóteses ou questões norteadoras e indicadores que fundamentem a interpretação final. A segunda etapa é a "exploração do material", momentos em que são colocadas em prática todas as decisões tomadas na pré-análise. É o momento da codificação dos dados brutos. Bardin (2009) diz que "esta fase, longa e fastidiosa, consiste essencialmente de operações de codificação, desconto ou enumeração, em função de regras previamente formuladas" (BARDIN, 2009, p. 101). No presente estudo, será feita uma categorização a partir de um esquema pré-definido -critérios de noticiabilidade - para que se obtenha as informações necessárias.

Por fim, a terceira e última fase é voltada para o "tratamento dos resultados". Nessa etapa os dados serão interpretados. "Os resultados brutos são tratados de maneira a serem significativos («falantes») e válidos” (BARDIN, 2009, p. 101). O analista, portanto, diante dos resultados obtidos, "pode então propor inferências e adiantar interpretações a propósito dos objetivos previstos, ou que digam respeito a outras descobertas inesperadas" (BARDIN, 2009, p. 101). 
$\mathrm{Na}$ presente pesquisa, utilizando o método de análise de conteúdo, a partir da definição dos critérios de noticiabilidade e valores-notícia, serão analisados dois programas Globo Esporte São Paulo, vinculados em outubro de 2015. A principal proposta é identificar a participação da mulher na produção de notícias dentro do recorte estabelecido do programa esportivo em questão.

Os critérios de noticiabilidade selecionados abaixo, servirão de apoio na aferição dos dados nas edições listadas: - Relevância: quanto mais "sentido" a notícia dá ao acontecimento, mais hipóteses a notícia tem de ser notada; - Notabilidade do assunto: quanto mais importante, mais visibilidade terá; - Novidade: almeja levar ao público o novo, informações atualizadas e contextualizadas; Inesperado/Curioso: o que surpreende; o conflito ou a controvérsia; - Rivalidade/Conflito: situações comuns no esporte, que também são fatores que se instalam nas situações noticiáveis;- Atualidade: remete ao que é novo; - Escândalo: situações que despertam grande interesse por ser pautada pela polêmica do fato; - Humor/Entretenimento: pautas mais leves, de interesse público. Além disso, no decorrer da análise interpretativa, o tempo também será um critério a ser analisado e comparado.

Seguindo as três principais etapas da Análise de Conteúdo de Laurence Bardin(2009), primeiramente é feito um primeiro contato com o material a ser analisado para que se possa fazer a decupagem das edições do Telejornal em questão, para observação dos principais critérios de noticiabilidade que se evidenciam no programa.

Após essa etapa, foram analisados os critérios de noticiabilidade elencados por Traquina (2005), Wolf (1995) e Sousa (2002). Selecionamos oito critérios de noticiabilidade a fim de comparar as reportagens feitas pelas mulheres e homens no Globo Esporte São Paulo. Os oito critérios delimitados foram: relevância, notabilidade do assunto, novidade, inesperado, rivalidade, atualidade, escândalo e humor/entretenimento.
Após, são elaboradas tabelas com os critérios de noticiabilidade selecionados, distribuídos em duas colunas: homem e mulher. Sendo assim, será possível uma melhor visualização dos dados aferidos na análise, possibilitando identificar a participação da mulher no Globo Esporte São Paulo, comparando o número de critérios de noticiabilidade presentes nas informações apresentadas pelos homens e mulheres no programa. O tempo também é um fato importante na análise para fins de comparação da duração das reportagens feitas pelas mulheres e homens no Globo Esporte São Paulo.

A partir dos critérios previamente selecionados, será elaborada uma tabela para cada edição escolhida, para melhor compreensão das informações apresentadas por ambos os gêneros.

Após a análise quantitativa dos dados, partiremos para a interpretação dos resultados apresentados seguido da análise das quatro edições selecionadas do Globo Esporte São Paulo, para verificar se, de acordo com os dados obtidos, a mulher possui participação semelhante à do homem no cenário televisivo esportivo do programa em questão.

\section{A Participação da Mulher no Globo Esporte São Paulo}

A partir deste tópico, serão analisadas as duas edições selecionadas do Globo Esporte São Paulo. Será feita uma análise quantitativa dos dados obtidos através da Análise de Conteúdo (BARDIN, 2009), os quais serão distribuídos em tabelas. Os resultados serão interpretados ao fim das análises, a fim de identificar, quantitativamente e qualitativamente, a participação da mulher no programa Globo Esporte São Paulo.

\section{Edição do dia 13 de outubro de 2015}

A edição do Globo Esporte São Paulo do dia 13 de outubro de 2015 foi ao ar numa terça-feira. O programa deste dia teve a apresentação de Ivan 
Moré e teve duração de 23 minutos e 23 segundos. O telejornal foi dividido em três blocos e abordou assuntos como o confronto entre Brasil e Venezuela, segundo jogo das eliminatórias para a Copa do Mundo, e abriu o programa com a informação da renúncia do presidente do São Paulo, Carlos Miguel Aidar. Abaixo estão os critérios selecionados dispostos em forma de tabela, para que seja possível uma melhor visualização da comparação dos dados obtidos na análise da edição.

Quadro 1 - Critérios encontrados nas informações da edição do dia 13 de outubro de 2015.

\begin{tabular}{lll}
\hline Critérios de Noticiabilidade & Mulher & Homem \\
\hline Relevância & $1 \mathrm{X}$ & $6 \mathrm{X}$ \\
\hline Notabilidade do assunto & $1 \mathrm{X}$ & $7 \mathrm{X}$ \\
\hline Novidade & $1 \mathrm{X}$ & $4 \mathrm{X}$ \\
\hline Inesperado & $1 \mathrm{X}$ & - \\
\hline Rivalidade & - & - \\
\hline Atualidade & $1 \mathrm{X}$ & $7 \mathrm{X}$ \\
\hline Escândalo & $1 \mathrm{X}$ & $1 \mathrm{X}$ \\
\hline Humor/entretenimento & $1 \mathrm{X}$ & $1 \mathrm{X}$ \\
\hline
\end{tabular}

Fonte: Autores.

Nesta edição, foram exibidas quatro reportagens sobre futebol, uma inserção ao vivo sobre a polêmica envolvendo o presidente do São Paulo, uma reportagem sobre surf, o quadro opinativo "Fala, Casão" e uma entrevista bem descontraída, em uma churrascaria, com o jogador Zeca, do Santos.

O programa já inicia com uma polêmica envolvendo a renúncia do presidente do São Paulo, o qual foi acusado de desvio de dinheiro e fraude. Portanto, esse episódio se encaixa no critério de escândalo e mostra-se de grande importância por ser um fato inesperado e polêmico envolvendo um clube de grande influência.

A repórter Natalie Gendra entrou ao vivo, direto do Centro de Treinamento do São Paulo, trazendo informações sobre a renúncia do presidente do clube. Natalie narra a situação da renúncia e atualiza o público sobre a situação no momento.
Boa tarde, Ivan. Boa tarde, todo mundo ligado no Globo Esporte. Essa reunião não vai mais acontecer, mas a renúncia permanece. A gente passou, en e o pessoal do globoesporte.com, a gente passou a manhã conversando com diretores, com conselheiros. Essa reunião ela foi adiada, ela foi cancelada na verdade pelo presidente Carlos Miguel Aidar. Mas o que ele deve fazer agora? Ele deve pegar a carta de renúncia dele e entregar na secretaria do conselho deliberativo do São Paulo. Essa reunião ela não era uma obrigação, ele não tinha que fazer essa reunião pra renunciar. Ele faria essa reunião pra dar a versão deles dos fatos, as acusações dele de fraude, de desvio de dinheiro, mas essa reunião não vai mais acontecer. ${ }^{5}$

$\mathrm{O}$ assunto polêmico e inesperado chamou a atenção do Brasil e Natali cumpriu o seu papel como jornalista, passando as informações de forma

5 Informação Verbal da repórter Natalie Gendra - Globo Esporte SP dia 13 de outubro de 2015. 
coerente e clara. A cobertura esportiva feita por Natalie foi realizada com ferramentas gerais do próprio jornalismo (BORELLI, 2002), portanto o gênero não alterou o conteúdo final e nem mudou o contexto da reportagem.

Logo após passar essas informações, Natalie faz um breve comentário sobre o time do São Paulo, alegando que "as coisas andavam bem mais leves" devido ao clima de descontração por conta do aniversário do zagueiro Breno e anuncia que o repórter Abel Neto tem mais informações sobre a preparação do time para o próximo jogo. Abel segue a reportagem elencando pontos importantes da preparação e adaptação do time do São Paulo com o novo técnico, Doriva. Além disso, aborda as polêmicas envolvendo a renúncia do presidente do clube. A reportagem conta com entrevistas de jogadores, dados estatísticos e boas imagens de apoio.

A seguir entra a reportagem de Guilherme Pereira, sobre a preparação do Palmeiras para conseguir alcançar o G4 do campeonato brasileiro. O repórter faz um levantamento sobre os adversários da equipe paulista e também faz uso de inúmeras fontes e entrevistas. Após o fim do primeiro bloco, Breno Dias vai ao ar trazendo informações sobre a competição internacional de surf, que ocorre na França. Dois brasileiros estão na semifinal da competição e mostram grande potencial de conseguirem disputar a final. Dessa forma, a reportagem é considerada de grande relevância, pois mostra o impacto dela para o telespectador, visto que o Brasil é grande potencial no surf e ganha destaque no exterior. A inserção da reportagem de Bruno Dias possui 1 minuto e 2 segundos.

O repórter Eric Faria trouxe informações sobre a preparação da Seleção Brasileira para as eliminatórias da Copa do Mundo de 2018, contra a Venezuela. A reportagem, com duração de 2 minutos e 31 segundos, conta com entrevista coletiva do técnico Dunga, junto ao jogador Daniel Alves.

Também nessa edição, o quadro opinativo "Fala, Casão" foi ao ar. Walter Casagrande entrou ao vivo e respondeu às perguntas dos telespectadores sobre a seleção brasileira, a qual iria enfrentar a Venezuela no mesmo dia. O quadro teve duração de 5 minutos e 21 segundos.

Logo depois, foi exibida a reportagem do Marco Aurélio Souza sobre a preparação do Corinthians para o próximo jogo no Campeonato Brasileiro e seus desfalques pra o confronto contra o Goiás. A reportagem teve duração de 2 minutos e 23 segundos.

Por fim, o repórter Renato Cury entrevista o lateral José Carlos Neto, o Zeca, do time do Santos em uma churrascaria da cidade. O jogador tem ganhado grande destaque nas últimas partidas devido ao seu bom desempenho. A conversa é bem descontraída e teve duração de 3 minutos e 42 segundos. O jornalismo esportivo tende a ser mais informal, porém, segundo Bravo (2009, p.26), deve-se ter cuidado para não confundir essa informalidade com sensacionalismo e acabar despriorizando a informação.

A inserção ao vivo de Natalie, sobre a polêmica envolvendo o presidente do São Paulo, foi a única presença feminina durante toda essa edição do Globo Esporte São Paulo e ela teve duração de apenas 1 minuto e 8 segundos. Porém, o assunto abordado mostra-se de grande relevância, além de ser inesperado, novo e polêmico.

Os critérios de maior ocorrência nesta edição foram: relevância, notabilidade do assunto e atualidade. O programa ocorre em época de campeonato brasileiro e Palmeiras, São Paulo, Santos e Corinthians - principais times de São Paulo - disputam o campeonato e, portanto, justifica-se a presença desses critérios na cobertura dos times em questão. 


\section{Edição do dia 22 de outubro de 2015}

Nesta edição, o programa tem duração de 24 minutos e é dividido em 3 blocos. Abaixo a tabela com os dados analisados:

Quadro 2 - Critérios encontrados na edição do dia 22 de outubro de 2015.

$\begin{array}{rll}\text { Critérios de Noticiabilidade } & \text { Mulher } & \text { Homem } \\ \text { 1. Relevância } & 1 \mathrm{X} & 6 \mathrm{X} \\ \text { 2. Notabilidade do assunto } & 1 \mathrm{X} & 6 \mathrm{X} \\ \text { 3. Novidade } & 1 \mathrm{X} & 5 \mathrm{X} \\ \text { 4. Inesperado } & - & 3 \mathrm{X} \\ \text { 5. Rivalidade } & - & 2 \mathrm{X} \\ \text { 6. Atualidade } & 1 \mathrm{X} & 5 \mathrm{X} \\ \text { 7. Escândalo } & - & 1 \mathrm{X} \\ \text { 8. Humor/entretenimento } & - & -\end{array}$

Fonte: Autores.

Na primeira parte, Ivan Moré e Caio Ribeiro fazem uma análise do último jogo entre São Paulo e Santos. São apontamentos táticos da partida e análise de erros cometidos pelos jogadores durante a partida. Para facilitar o entendimento de cada lance e dar mais dinâmica ao quadro de opinião, ilustrações foram adicionadas às imagens do jogo. Após os primeiros comentários sobre a partida, o repórter Renato Cury entra ao vivo entrevistando o atacante Marquinhos Gabriel, autor de um dos gols do Santos. A inserção se mostra relevante, pois faz um "gancho" e complementa o assunto anterior, enriquecendo a cobertura trazendo fontes. O quadro de opinião teve duração de 5 minutos no programa.

$\mathrm{Na}$ segunda parte, Ivan noticia os resultados da Liga dos Campeões. Num primeiro momento, o apresentador narra os principais lances da partida entre Paris Saint Germain (PSG) e Real Madrid e faz uso de muitas imagens que acompanham a sua narrativa. O fato foi elencado como relevante, notório, atual e também inesperado porque a partida, mesmo tendo jogadores "craques" como Cristiano Ronaldo e Zlatan Ibrahimovic, terminou sem gols.

“É até estranho, né? Que um jogo entre PSG e Real Madrid tenha ficado em 0 x 0, e ficou[... ", 6

A primeira reportagem do programa é sobre a partida entre Fluminense e Palmeiras. Foi a primeira matéria em que podemos aferir o critério "Rivalidade/conflito", elencado pela autora LiChang Shuen Sousa (2002). Os jogadores do Palmeiras, Vitor Ramos e Dudu se desentenderam durante a partida e saiu com o "clima muito quente com os jogadores dentro de campo" ". A narrativa do repórter Marco Aurélio Souza é informal e possui marcas de dramatização, enquanto as imagens apresentam os momentos do desentendimento. Segundo Baggio (2012), as imagens na televisão são essenciais porque facilitam o entendimento e chamam mais atenção, deixando a narrativa mais interessante.

6 Informação verbal do apresentador Ivan Moré - Globo Esporte SP, 22 de outubro de 2015.

7 Informação verbal do repórter Marco Aurélio Souza - Globo Esporte SP, 22 de outubro de 2015. 
A partir daí a maior parte da cobertura é focada no conflito da partida. Entrevistas com jogadores e com o técnico do Palmeiras são apenas depoimentos sobre a confusão em campo.

O clima seguiu quente dentro da área. Marlon, do Fluminense, tentou tirar Dudu da confusão. O camisa 7 por pouco não brigou com Vitor Hugo. Zé Roberto, então, pediu calma. E Leandro Vuaden, para a sorte do Palmeiras, preferiu um sermão quando até poderia ter dado um cartão. No espaço sagrado do vestiário, teve mais. [...]. Na noite em que a torcida viu um jogo com três uniformes e na mesma noite, que depois de uma briga, nasceu um novo Palmeiras, o placar foi 2 a $1 .{ }^{8}$

Logo após, Caio Ribeiro volta ao cenário para comentar os lances da partida, complementando a reportagem anterior.

Joanna de Assis é a única presença feminina no programa. A repórter faz uma cobertura do treino do Corinthians, que é líder no Brasileirão e possui melhor campanha na competição, com melhor ataque e melhor defesa. Joanna traz dados sobre a campanha do time até o momento e informações pertinentes da preparação para a próxima partida.

"É, mas pra este domingo a coisa tá complicada, viu? Tite tem cinco titulares 'pendurados' com dois cartões amarelos. Cássio, Elias, Renato Augusto, Malcon e Vagner Love. E tomar mais um cartão significa perder uma verdadeira final de campeonato brasileiro". 9

A reportagem tem duração de 1 minuto e 44 segundos e Joanna faz uso de fontes para dar mais credibilidade aos fatos, entrevistando jogadores na coletiva de imprensa.
"Se vocês tomarem um cartãozinho, vocês vão perder uma final contra o Atlético Mineiro. Vocês se tocaram disso? Dá medinho de ficar fora desse jogo, porque esse jogo é a final, né? "'10

Quando volta ao estúdio, Ivan Moré divulga a lista de convocados pelo técnico da seleção, para as eliminatórias da Copa do Mundo de 2018.

A última reportagem do programa é feita pelo repórter Guilherme Pereira e é a que tem mais tempo no ar: 7 minutos. A cobertura é de grande relevância, pois é um clássico paulista entre São Paulo e Santos, bastante disputado, na primeira semifinal da Copa do Brasil. Foi um jogo com situações inesperadas: tempestade e queda de energia. O repórter faz diversas relações com as situações inesperadas aqui descritas.
Algumas circunstâncias num jogo são incontroláveis. Outras dependem da competência ou da falta dela. O quanto um temporal pode atrapalhar um clássico como esse? O quanto a insistência em pedir a bola pode dar certo? O quanto cinco minutos podem ser determinantes pra mudar uma história? $O$ quanto é fundamental um time ser mais eficiente que outro? [...] O São Paulo sabia que era necessário fazer um bom resultado no Morumbi, por isso o clima de decisão. Do outro lado estava um time em grande fase, preparado pra acabar com qualquer esperança do rival. Só que aí, [imagens: as luzes do estádio se apagam] a primeira circunstância incontrolável da noite. [...] Nas pernas do Rogério a ansiedade para que as luzes voltassem rapidamente. [...]

Logo depois do gol do São Paulo, veio a segunda circunstância incontrolável da noite. A chuva virou tempestade e a tempestade virou dilúvio. Ficou difícil jogar futebol, ficou difícil enxergar o jogo e os entrevistados [imagens

\footnotetext{
8 Idem.

9 Informação verbal da repórter Joanna de Assis - Globo Esporte SP, dia 22 de outubro de 2015.

${ }^{10}$ Pergunta da repórter Joanna de Assis ao jogador Vagner Love, do Corinthians - Globo Esporte SP, dia 22 de outubro de 2015.
} 
borradas e lente da câmera molhada]. Olha, ficou dificil de mostrar até pra vocês o quanto chovia porque nem o microfone aguentou tanta àgua. O primeiro tempo terminou com o gramado desse jeito aí ó [imagens do gramado enxarcado], o torcedor tentou se esconder e os jogadores se preparavam para o que estava por vir. [...] Numa noite cheia de circunstâncias diferentes. Pra um sobraram os gols, pro outro a escuridão e a tormenta. ${ }^{11}$

Novamente as imagens foram fundamentais para complementar a narrativa do repórter. Como destacam Negrini e Brandalise (2015), o uso de imagens permite "[...] a possibilidade de uma narrativa televisual de forma espetacular e humanizada; o destaque do fato ocorrido no contexto de abrangência do telejornal e o potencial caráter melodramático relacionado ao fato." (NEGRINI; BRANDALISE, 2015, p. 9). Segundo Sousa (2002, p. 4), "no esporte, as imagens são a notícia em si: o registro do gol, da falta, da bela jogada". A reportagem de Guilherme foi dinâmica e fez uso de uma boa narrativa, causando impacto emocional, por ser um clássico e apresentando um potencial espetacular, fazendo uso de boas imagens (SOUSA, 2002, p. 2).

Ao final da reportagem, Ivan Moré divulga uma pequena nota sobre a punição do goleiro do São Paulo, Rogério Ceni, junto ao STJD (Superior Tribunal de Justiça Desportiva), devido a declaração polêmica feita por ele na última partida contra o Vasco.

No total, foram 3 reportagens e apenas uma delas foi feita por uma mulher. A participação de Joanna de Assis, comparado à do homem, é mínima. Como afirma Aguiar (2012, p. 35), as mulheres ainda têmque lutar bastante para receber o mesmo reconhecimento que seus colegas de trabalho recebem, sem distinção e que seu trabalho seja qualificado como bom ou ruim apenas pelo conteúdo apresentado.

Percebe-se, no programa analisado, que o tempo destinado aos comentários de Caio oi maior. Foram 5 minutos destinados a análises de táticas e lances do jogo ente São Paulo e Santos.

A última reportagem apresentada foi a mais longa, com 7 minutos. Tudo isso porque ela possui uma das maiores motivações no futebol: um clássico. Geralmente é um jogo mais disputado, causando conflito. Talvez este fato explique o tempo destinado a ela. Como afirma Sousa (2012), no esporte, "a noticiabilidade também se pauta pelo conflito que se instala nas situações noticiáveis" (SOUSA, 2002, p.11);

No total, a reportagem de Joana de Assis possui somente 4 critérios enquanto o somatório das participações dos homens no programa é28. Essa diferença se dá obviamente pela diferença do número de reportagens feitas por cada um.

Novamente a presença feminina no programa é muito inferior a do homem e essa diferença também é evidente no que se refere ao tempo. Enquanto os homens foram ao ar durante quase 18 minutos no total, Joanna teve apenas 1 minuto e 44 segundos.

\section{Considerações Finais}

Durante muito tempo, as mulheres desempenharam funções secundárias e em diversos aspectos foram coadjuvantes de funções desempenhadas por homens. No jornalismo esportivo não foi diferente, as mulheres tiveram que lutar muito para ocupar lugares considerados masculinos. Até a década de 1980 era praticamente impossível uma mulher entrar em um campo futebol. Segundo Aguiar (2012), elas eram consideradas sexo frágil e deveriam se manter em segurança para gerarem filhos fortes e saudáveis.

${ }^{11}$ Idem. 
No entanto, ao longo dos anos e através de diversas lutas sociais, as mulheres começaram a ocupar seu espaço nas redações jornalísticas, nos campos de futebol, nas quadras esportivas, etc. Nas editorias esportivas, o número de jornalistas que trabalham com futebol passou de oito para 90, se comparado à década de 1980 .

$\mathrm{Na}$ presente pesquisa foram analisadas duas edições do programa Globo Esporte São Paulo e, dessa forma, com a aferição dos dados, seguindo o método de análise de conteúdo (BARDIN, 2009), concluímos que no programa Globo Esporte São Paulo, a mulher não possui participação semelhante à do homem no cenário televisivo esportivo do programa.

O cenário do jornalismo esportivo ainda é mascarado com um certo preconceito com a figura da mulher. Notou-se durante a pesquisa a escassa participação da mulher no programa escolhido e encontramos alguns obstáculos ao selecionarmos as edições, devido à falta de mulheres no telejornal esportivo.

A pesquisa conclui que a presença da mulher no telejornalismo esportivo cresceu muito ao longo dos anos, mas que ainda não é igual, nem mesmo semelhante, ao espaço ocupado por homens. Embora a o programa Globo Esporte seja um veículo de comunicação em que se verifica a constante presença feminina, aferiu-se neste trabalho, na edição Paulista, que a participação dela ainda é pequena comparada ao homem.

\section{Referências}

AGUIAR, E. F. de. Telejornalismo esportivo: a mulher no mundo do futebol. uma análise do Programa Globo Esporte Ceará. 2012. Monografia (Curso de Comunicação Social, Habilitação em Jornalismo) - Centro de Ensino Superior do Ceará, Faculdade Cearense, 2012. Disponível em: https://bit.ly/35rqUa6. Acesso em: 11 out. 2018.

BAGGIO, L. M. Representação da mulher no telejornalismo esportivo: a atuação da jornalista Renata Fan no Programa Jogo Aberto da Tv Bandeirantes. 2012. Trabalho Final de Graduação (Bacharelado em
Jornalismo) - Centro Universitário Franciscano, Santa Maria, RS, 2012. Disponível em: https://bit.ly/2shDAlT. Acesso em: 9 nov. 2018.

BARDIN, L. Análise de conteúdo. Lisboa: Edições 70, 2009.

BORELLI, V. O esporte como uma construção específica no campo jornalístico. In: CONGRESSO BRASILEIRO DE CIÊNCIA DA COMUNICAÇÃO, 25., Salvador, BA, 2002. Anais [...]. Salvador: INTERCOM, 2002. p. 1-22.

BRAVO, D. V. T. Elas assumiram o comando: as mulheres jornalistas no mundo do telejornalismo esportivo. 2009. Monografia (Graduação em Comunicação Social/ Jornalismo) - Universidade Federal de Viçosa, Minas Gerais, 2009. Disponível em: http://www.com.ufv.br/ pdfs/tccs/2009/deborabravo.pdf. Acesso em: 22 out. 2018.

CARVALHO, D. J. A conquista da cidadania feminina. Saber Acadêmico: Revista Multidisciplinar da UNIESP, Presidente Prudente, SP, n. 11, p. 143-153, jun. 2011. Disponível em: http://www.uniesp.edu.br/revista/ revista11/pdf/artigos/12.pdf. Acesso em: 29 nov. 2018.

COELHO, P. V. Jornalismo esportivo. São Paulo: Editora Contexto, 2003.

GOMES, R. A análise de dados em pesquisa qualitativa. In: MINAYO, M. C. de S. (org.). Pesquisa social: teoria método e criatividade. 22. ed. Petrópolis: Vozes, 2003.

LIIDTKE, D. A imprensa de salto alto. 2012. Disponível em https://bit.ly/2OgC77O. Acesso em: 10 nov. 2018.

LORÊDO, J. Era uma vez... a televisão. São Paulo: Alegro, 2000.

MEMÓRIA GLOBO. Isabela Scalabrini. Rio de Janeiro, RJ: Globo Comunicações e Participações, 2013.

MOTTA, L. G. Teoria da notícia: as relações entre o real e o simbólico. In: MOUILLAUD, M.; PORTO, S. D. (org.). O jornal: da forma ao sentido. Brasília: Editora Universidade de Brasília, 2002.

NEGRINI, M.; BRANDALISE, R. Os critérios de noticiabilidade no telejornalismo: uma reflexão a partir da tragédia de Santa Maria. Revista Pauta Geral-Estudos em Jornalismo, Ponta Grossa, v. 2, n. 1, p. 74-90, jan./ jun.2015. Disponível em: https://bit.ly/2XHCg7p. Acesso em: 29 nov. 2018.

OLIVEIRA. Ana Paula. A importância do papel da mulher na sociedade. 2006. Disponível em: https://bit. ly/37CIoSY. Acesso em 23 de novembro de 2019.

PATERNOSTRO, V. I. $O$ texto na $T V$ : manual de telejornalismo. 2. ed. Rio de Janeiro: Campus, 2006. 
PRIZIBISCZKI, C. Maria Helena Rangel: há 60 anos, a presença feminina no jornalismo esportivo tinha início. Portal Imprensa: Jornalismo e Comunicação na Web, São Paulo, SP, 9 ago. 2007. Disponível em: https://bit. ly/2shkDj9. Acesso em: 29 nov. 2018.

REZENDE, O. Conheça a trajetória da primeira jornalista de esportes do Brasil, Portal Mídia Esporte. 2014. Disponível em: https://bit.ly/2OiRaOo. Acesso em: 17 out. 2018.

RIBEIRO, A. Os donos do espetáculo: histórias da imprensa esportiva do Brasil. São Paulo: Editora Terceiro Nome, 2007.

RIXA. Almanaque da TV: 50 anos de memória e informação. Rio de Janeiro: Objetiva, 2000.

ROCHA D.; ABREU, A. A. de (org.). Elas ocuparam as redações: depoimentos ao CPDOC. Rio de Janeiro: Editora FGV, 2006.

SCOTT, G. P. Mulher, corpo e credibilidade: um estudo cartográfico sobre as apresentadoras dos principais telejornais do país. 2013. Trabalho de Conclusão de Curso (Bacharel em Comunicação Social: Habilitação em Jornalismo) - Faculdade de Biblioteconomia e Comunicação, Universidade Federal do Rio Grande do Sul, Porto Alegre, RS, 2013. Disponível em: https://bit. ly/34gi13a. Acesso em: 9 set. 2018.
SOUSA, L.-C. S. C. S. Cobertura esportiva na televisão: critérios de noticiabilidade na interface entre jornalismo e entretenimento. 2002. Disponível em: https://bit. ly/2XJTpgA. Acesso em: 14 set. 2018.

TRAQUINA, N. Teorias do jornalismo: porque as notícias são como são. Florianópolis: Insular, 2005. v. 1.

WOITOWICZ, K. J. Traços do feminismo na imprensa alternativa: as lutas das mulheres nos jornais Opinião, Movimento e Repórter nos anos 1970 no Brasil. In: VII SEMINÁRIO INTERNACIONAL FAZENDO GÊNERO, 7., 2006, Florianópolis, SC. Florianópolis: Mulheres, 2006.p. 1-7. Tema: Gênero e preconceitos.

WOITOWICZ, K. J.; PEDRO, J. M. O movimento feminista durante a ditadura militar no Brasil e no Chile: conjugando as lutas pela democracia política com o direito ao corpo. Espaço Plural, Marechal Cândido Rondon, v. 2, p. 43-55, 2009.

WOLF, M. Teorias da comunicação. Lisboa: Editorial Presença, 1995. 